\title{
Becoming United through Core Values
}

\author{
Lauza Saulnier
}

L

ast fall, the 70th Annual General Meeting of the Canadian Society of Hospital Pharmacists (CSHP) was held in Fredericton, New Brunswick. Board members and branch council members from across the country conducted meetings, attended the educational program, and joined in the 50th anniversary celebration of the CSHP's New Brunswick Branch.

Witnessing the tireless work and dedication of CSHP volunteers and staff and the camaraderie among members made me ponder the question, "What does it mean to be a CSHP member?"

Members share common bonds through CSHP's values. CSHP provides opportunities to network with colleagues from other regions and learn about innovative practices, to discover new areas of interest, to participate in rewarding experiences, and to contribute to the advancement of the profession while belonging to a vibrant community of practice. Here are some tangible examples of how CSHP values support Society members in providing excellent pharmacy practice integral to patient-centred care:

- Excellence and innovation in patient care, through publications such as Pharmacy Practice in Hospitals and Other Collaborative Healthcare Settings: Position Statements, which express the CSHP's stance and describe a desired and achievable level of performance that is applicable to the practice of pharmacy; through programs such as Excellence in Hospital Pharmacy, an initiative that focuses members' efforts on improving patient health outcomes through patient engagement, best practice, effective communication, and collaborative practice; and through accreditation standards for postgraduate pharmacy residency training programs, established by the Canadian Pharmacy Residency Board.

- Interprofessional collaboration, through strong partnerships with external stakeholders and effective advocacy for excellent pharmacy practice, by responding to requests for relevant consultations and collaborating with national organizations.

- Professional development and mentorship, made available to members through services and events that lead and inspire excellent pharmacy practice, such as the Canadian Journal of Hospital Pharmacy, the Professional Practice Conference, the Harrison Pharmacy Management Seminar, and an array of educational programs offered by CSHP Branches; and through

Pharmacy Specialty Networks, which facilitate nationwide networking and communication among individuals who share common professional practice interests.

- Recognition of members' dedication to our Society and the profession through the Awards Program, which acknowledges members who have

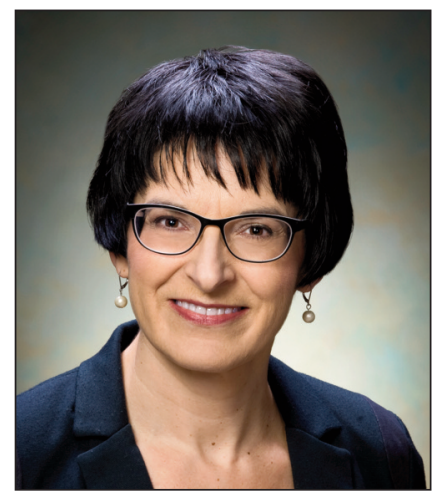
distinguished themselves within the profession or have completed projects of importance to pharmacy practice; and through recognition of volunteers who contribute to CSHP activities at the national or branch level, generously giving time, sharing knowledge and life experiences to advance pharmacy practice, and helping the Society to achieve its goals and objectives.

- Accountability to members, through public reporting of the CSHP Balanced Scorecard 2015-2020, which highlights key performance indicators and progress toward achievement of organizational goals; and through semi-annual reporting by provincial branches, affiliated boards, and committees on how their objectives and actions are integrated within corporate strategic priorities and progress to date.

Over the past year, I have had the privilege of meeting and working with many enthusiastic and committed volunteers who help to shape the future and contribute to changes that will positively affect patient health outcomes. I am proud to be a CSHP member and to be part of a thriving, progressive Society, leading and inspiring excellent pharmacy practice integral to patient-centred care in hospitals and other collaborative healthcare settings.

Lauza Saulnier, BSc(Pharm), ACPR, is Past President and Vision Liaison for the Canadian Society of Hospital Pharmacists. 